\title{
CONTINUUM SOLUTIONS FOR LONG-WAVE EXTENSIONAL BUCKLING OF REGULAR FRAMES
}

\author{
Z. P. BAŽANT $\dagger$ and M. CHRISTENSEN $\ddagger$ \\ Department of Civil Engineering, Northwestern University, Evanston, Illinois 60201, U.S.A.
}

\begin{abstract}
Using approximation by a micropolar continuum, the extensional buckling of a multi-story, multibay rectangular frame with rectangular boundary is solved by formulating the problem in terms of a system of six linear ordinary differential equations. The buckling loads must be computed by a trial-and-error procedure because all coefficients of the $6 \times 6$ determinant to vanish depend on explicitly inexpressible complex roots and eigenvectors of another $6 \times 6$ determinant which in turn depends nonlinearly on the initial stress. It is shown that for tall frames consideration of long-wave buckling loads is important. Also, the continuum approximation is found to give very accurate results, as compared with the exact solutions of large frames.
\end{abstract}

WHILE in low building frames the axial extensions of members may be usually neglected, in tall frames they must be taken into account. Buckling modes of such frames are then of long-wave character and the whole building frame appears to buckle as a single column. Analysis of such buckling modes with the usual methods becomes intractable for truly large frames, because of the overwhelmingly large number of unknown displacements of joints. As a rule, however, large frames are of regular character. This fact may be advantageously utilized introducing a continuum approximation of the frame, which has been developed in detail in a previous article[1] and has been found to lead to an orthotropic micropolar continuum of Eringen [2].

The aim of the present paper is to present a solution of long-wave buckling of a large regular rectangular frame, with rectangular boundary, using the micropolar continuum approximation. All columns of the frame will be considered to have equal cross sections and equal initial axial forces, and the same will be assumed for the beams. This simplification with regard to practical situations is introduced for two reasons. First, it makes possible an analytical solution and, second, the results may be compared with the exact solution which can be obtained by the methods of finite difference calculus, as has been shown elsewhere[3]. The comparison will show that the present solution is simpler and, especially, that the error committed by using the continuum approximation is, for a large frame, very small indeed. This fact will give confidence in the use of the continuum approximation for frames with variable member properties and axial forces or frames of other boundary shapes and boundary conditions, for which the solution of the type presented here is not feasible. In such cases the continuum approximation may serve as a basis for numerical solutions by the finite difference method (or finite element method), leading to a substantial reduction in the number of unknown displacement parameters [1]. (A detailed description of such applications of the continuum approximation is given in a separate article [4].)

The method of solution expounded in the sequel bears, in spite of greater complexity, some marks of similarity with the solutions for buckling of rectangular in- 
compressible non-polar solids, which have been given by Biot[5], Wu and Widera[6] and Bažant [7].

\section{MATHEMATICAL FORMULATION OF THE PROBLEM}

Let us consider a planar rectangular frame (Fig. 1) which is initially in equilibrium under initial axial forces $P_{y}^{0}$ in all columns and $P_{x}^{0}$ in all beams. Subsequently, the initial equilibrium is disturbed by infinitely small incremental applied forces at the sides of frame and applied forces $f_{x}, f_{y}$ and moments $m$ per unit area. The incremental equilibrium equations for horizontal forces, vertical forces and bending moments acting on a joint may be approximated by the following three partial differential equations [1]:

$$
\begin{aligned}
& E_{x}^{\prime} L_{x}^{2} u_{, x x}+k_{y} s_{y}^{\prime \prime} u_{, y y}+2 k_{y} s_{y}^{\prime} \phi_{, y}+f_{x}=0 \\
& E_{y}^{\prime} L_{y}^{2} v_{, y y}+k_{x} s_{x}^{\prime \prime} v_{, x x}-2 k_{x} s_{x}^{\prime} \phi_{, x}+f_{y}=0 \\
& 2 k_{x} s_{x}^{\prime}\left(\phi-v_{, x}\right)+2 k_{y} s_{y}^{\prime}\left(\phi+u_{, y}\right)+L_{x}^{2} k_{x} s_{x} c_{x} \phi_{, x x}+L_{y}^{2} k_{y} s_{y} c_{y} \phi_{, y y}-m=0 .
\end{aligned}
$$

Here $x, y=$ horizontal and vertical cartesian coordinates (Fig. 1); subscripts $x, y$ refer to members in the horizontal and vertical directions but those following a comma denote partial derivatives, e.g. $u_{x x}=\partial^{2} u / \partial x^{2}, \phi_{, y}=\partial \phi / \partial y ; u, v, \phi=$ continuous twice differentiable functions of $x, y$ representing horizontal and vertical joint displacements and joint rotations (positive if counterclockwise); $L_{x}, L_{y}=$ length of horizontal and vertical members; $E_{x}^{\prime}=E A_{x} / L_{x}, E_{y}^{\prime}=E A_{y} / L_{y}$ where $A_{x}, A_{y}=$ cross section areas; $k_{x}=E I_{x} / L_{x}, k_{y}=E I_{y} / L_{y}$ where $I_{x}, I_{y}=$ cross sectional moments of inertia; $s_{x}, c_{x}$ or $s_{y}, c_{y}=$ the well-known stability functions of $P_{x}^{0}$ and $P_{y}^{0}$, which are expressed, in the case of constant cross-section, as follows (see [8], e.g.):

$$
\begin{array}{ll}
s=\frac{\alpha(\sin \alpha-\alpha \cos \alpha)}{2-2 \cos \alpha-\alpha \sin \alpha}, \quad c=\frac{\alpha-\sin \alpha}{\sin \alpha-\alpha \cos \alpha} \quad\left(P^{0}>0\right) \\
s=\frac{\alpha(\alpha \operatorname{ch} \alpha-\operatorname{sh} \alpha)}{2-2 \operatorname{ch} \alpha+\alpha \operatorname{sh} \alpha}, \quad c=\frac{\operatorname{sh} \alpha-\alpha}{\alpha \operatorname{ch} \alpha-\operatorname{sh} \alpha}\left(P^{0}<0\right)
\end{array}
$$

(a)

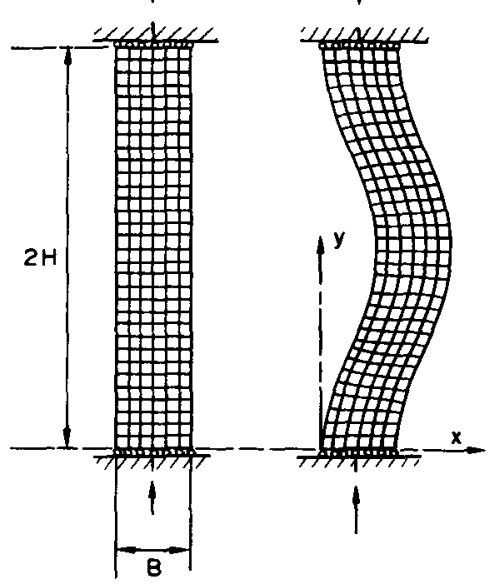

(c)
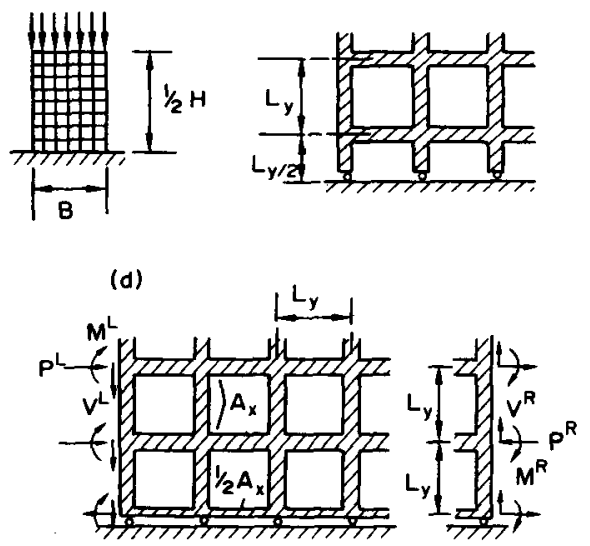

Fig. 1. (a) The geometry of the frame solved; (b) The long-wave buckling mode; (c) The free standing frame of approximately the same buckling load; (d) Detail of the boundaries of the frame solved; (e) An alternate boundary support which could be analyzed similarly. 
where $\alpha=\sqrt{ }\left(\left|P^{0}\right| L / k\right)$ and $s=4, c=1 / 2$ for $P^{0}=0$. (When the cross-section is variable along each member, the $s$ and $c$ functions may be obtained numerically.) Finally,

$$
s^{\prime}=s(1+c), s^{\prime \prime}=2 s^{\prime}-P^{0} L / k \text {. }
$$

To make an analytical solution possible, the frame of rectangular boundary will be considered to be compressed on top and bottom between two rigid frictionless plates which slide on the frame, except that the central point is fixed, as is shown in Fig. 1. This is not a practical case but numerical analyses have shown that the buckling load of this frame is almost the same as the buckling load for the usual case of a free-standing frame fixed at the base if its height equals 1/4 of the height of the frame considered here and the properties are identical. Furthermore, because the horizontal incremental axial forces are negligible, as the analysis below will confirm, the solution for a frame with completely fixed top and bottom boundaries will be almost the same.

The buckling mode will be assumed to be sinusoidal in the vertical direction,

$$
\begin{aligned}
& u(x, y)=U_{0}-U(x) \cos \gamma y \\
& v(x, y)=V(x) \sin \gamma y \\
& \phi(x, y)=R(x) \sin \gamma y
\end{aligned}
$$

where $U, V, R$ are functions of $x$ only and $U_{0}, \gamma$ are constants, $\gamma=\pi / H$. These expressions identically satisfy the conditions on displacements at the bottom and top boundaries, namely $v=\phi=0$ for $y=0$ and $y=2 H$. The expression for the shear stress $\sigma_{y x}$ at these boundaries is [1] $\left(k_{y} s_{y}^{\prime \prime} u_{, y}+2 k_{y} s_{y}^{\prime} \phi\right) / L_{x} L_{y}$ and it is seen that it also vanishes identically, as is required by the third and last of the boundary conditions on top and bottom.

The joints at the free left and right faces of the frame will be considered to have no incremental applied moments $M^{L}, M^{R}$ and vertical forces $T^{L}, T^{R}$ but in general to have a nonzero incremental horizontal applied force $P^{L}, P^{R}$, positive when oriented into the frame. The boundary conditions are most conveniently expressed when the frame is imagined to extend beyond the actual boundary joints at the sides of the frame, and the continuum boundary is imagined to be located at midlength of the first imaginary beams extending beyond the boundary (in detail, see [1]). The continuum approximations to the incremental axial compressive force, shear force and bending moment in the horizontal beams are (cf. [1]):

$$
\begin{gathered}
P_{x}=-L_{x} E_{x}^{\prime} u_{, x}, \quad T_{x}=\left(k_{x} s_{x}^{\prime \prime} v_{, x}-2 k_{x} s_{x}^{\prime} \phi\right) / L_{x} \\
M_{x}=\frac{1}{2} L_{x} k_{x} s_{x}\left(1-c_{x}\right) \phi_{, x} .
\end{gathered}
$$

The boundary conditions at the left side $x=-a$ are $P^{L}=P_{x}^{0}, T^{L}=T_{x}, M^{L}=M_{x}-$ $\left(T^{L}+P_{x}^{0} v_{, x}\right) L_{x} / 2$ and those at the right side $x=a$ are obtained by replacing $M_{x}$ with $-M_{x}[1]$, the positive sense of $T^{L}, T^{R}, M^{L}, M^{R}$ being considered the same as for the force upon boundary joint due to the internal forces in the imaginary members. Substituting (5), and $T^{L}=T^{R}=M^{L}=M^{R}=0$, the boundary conditions at the sides take the form:

$$
\begin{gathered}
P^{L}=-L_{x} E_{x}^{\prime} u_{, x} \text { for } x=-a ; \quad P^{R}=-L_{x} E_{x}^{\prime} u_{, x} \text { for } x=a \\
s_{x}^{\prime \prime} v_{, x}=2 s_{x}^{\prime} \phi, \quad k_{x} s_{x}\left(1-c_{x}\right) \phi_{, x}= \pm P_{x}^{0} v_{, x} \text { for } x=\mp a .
\end{gathered}
$$

In the sequel it will be further assumed that $P^{R}=-P^{L}$, which means that only 
antisymmetric deformations and buckling modes will be considered because they can be naturally expected to yield much lower buckling loads than the buckling modes in which the frame deforms symmetrically about the vertical axis (bulging).

When expressions (4) are substituted into (1), all functions of $y$ may be eliminated and (1) is reduced to a system of three ordinary differential equations

$$
\begin{aligned}
& -\left(E_{x}^{\prime} L_{x}^{2}\right) U_{, x x}+\left(\gamma^{2} k_{y} s_{y}^{\prime \prime}\right) U+2\left(\gamma k_{y} s_{y}^{\prime}\right) R=-X(x) \\
& -\left(\gamma^{2} E_{y}^{\prime} L_{y}^{2}\right) V+\left(k_{x} s_{x}^{\prime \prime}\right) V_{, x x}-2\left(k_{x} s_{x}^{\prime}\right) R_{, x}=-Y(x) \\
& 2\left(\gamma k_{y} s_{y}^{\prime}\right) U-2\left(k_{x} s_{x}^{\prime}\right) V_{, x}+\left(2 k_{x} s_{x}^{\prime}+2 k_{y} s_{y}^{\prime}-\gamma^{2} L_{y}^{2} k_{y} s_{y} c_{y}\right) R+\left(L_{x}^{2} k_{x} s_{x} c_{x}\right) R_{, x x}=M(x) .
\end{aligned}
$$

To make analytical solution possible, the incremental horizontal loads at the sides of frame will be assumed to be sinusoidally distributed,

$$
P^{L}=-P^{R}=P^{*} \cos \gamma y
$$

where $P^{*}=$ constant. The boundary conditions on $U, V$ and $R$ result by substituting (4) and (8) into (7),

$$
L_{x} E_{x}^{\prime} U_{, x}= \pm P^{*}, s_{x}^{\prime \prime} V_{, x}=2 s_{x}^{\prime} R, k_{x} s_{x}\left(1-c_{x}\right) R_{, x}= \pm P^{0} V_{, x} \text { for } x=\mp a .
$$

\section{COMPUTATION OF CRITICAL LOADS}

The problem has been formulated in terms of a system of three simultaneous secondorder ordinary linear differential equations (7) with six boundary conditions (9). For the analytical solution it is convenient to transform equations (7) to a system of six first-order equations by defining six new unknown functions of $x$,

$$
F_{1}=U, F_{2}=U^{\prime}, F_{3}=V, F_{4}=V^{\prime}, F_{5}=R, F_{6}=R^{\prime} .
$$

where primes stand for derivatives. If these variables are substituted into (7) and the relations $F_{2}^{\prime}=F_{1}, F_{4}^{\prime}=F_{3}, F_{6}^{\prime}=F_{5}$ are included, the following system of first-order equations may be obtained:

where

$$
\left\{\begin{array}{l}
F_{1}^{\prime} \\
F_{2}^{\prime} \\
F_{3}^{\prime} \\
F_{4}^{\prime} \\
F_{5}^{\prime} \\
F_{6}^{\prime}
\end{array}\right\}=\left[\begin{array}{llllll}
0 & 1 & 0 & 0 & 0 & 0 \\
a_{21} & 0 & 0 & 0 & a_{25} & 0 \\
0 & 0 & 0 & 1 & 0 & 0 \\
0 & 0 & a_{43} & 0 & 0 & a_{46} \\
0 & 0 & 0 & 0 & 0 & 1 \\
a_{61} & 0 & 0 & a_{64} & a_{65} & 0
\end{array}\right]\left\{\begin{array}{l}
F_{1} \\
F_{2} \\
F_{3} \\
F_{4} \\
F_{5} \\
F_{6}
\end{array}\right\}
$$

$$
\begin{array}{ll}
a_{21}=\gamma^{2} k_{y} s_{y}^{\prime \prime} /\left(E_{x}^{\prime} L_{x}^{2}\right), & a_{25}=2 \gamma k_{y} s_{y}^{\prime} /\left(E_{x}^{\prime} L_{x}^{2}\right) \\
a_{43}=\gamma^{2} E_{y}^{\prime} L_{y}^{2} /\left(k_{x} s_{x}^{\prime \prime}\right), & a_{46}=2 k_{x} s_{x}^{\prime} /\left(k_{x} s_{x}^{\prime \prime}\right) \\
a_{61}=-2 \gamma k_{y} s_{y}^{\prime} /\left(L_{x}^{2} k_{x} s_{x} c_{x}\right), & a_{64}=2 k_{x} s_{x}^{\prime} /\left(L_{x}^{2} k_{x} s_{x} c_{x}\right) \\
a_{65}=-\left(2 k_{x} s_{x}^{\prime}+2 k_{y} s_{y}^{\prime}-\gamma^{2} L_{y}^{2} k_{y} s_{y} c_{y}\right) /\left(L_{x}^{2} k_{x} s_{x} c_{x}\right) .
\end{array}
$$


Note that the coefficients of equation (11) are not symmetrical, although those of the original equations (7) are.

Because the coefficients of equations (11) are constant, the solution may be sought in the form

$$
F_{i}=K_{i} \mathrm{e}^{\lambda x} \quad(i=1,2, \ldots, 6)
$$

Substitution into (11) yields a system of homogeneous linear algebraic equations for $K_{i}$ which admit non-zero solution only if their determinant vanishes. This condition requires that the admissible values for $\lambda$ are the eigenvalues of the matrix of equations (11). The equation for $\lambda$ (characteristic equation) may be brought to the form

$$
\begin{array}{r}
\lambda^{6}-\left(a_{21}+a_{65}+a_{43}+a_{46} a_{64}\right) \lambda^{4}+\left(a_{21} a_{65}+a_{21} a_{43}+a_{43} a_{65}-a_{25} a_{61}+a_{21} a_{46} a_{64}\right) \lambda^{2} \\
-\left(a_{21} a_{43} a_{65}-a_{25} a_{43} a_{61}\right)=0
\end{array}
$$

which is a cubic equation for $\lambda^{2}$. (Thus, if $\lambda$ is a root, so is $-\lambda$.) There are six roots $\lambda=\lambda_{1}, \lambda_{2}, \ldots, \lambda_{6}$ which are in general complex (although in practical computations $\lambda_{1}, \ldots, \lambda_{4}$ were usually real and $\lambda_{5}, \lambda_{6}$ imaginary). The roots will be assumed to be all distinct, i.e. no double roots exist. (This has been found to occur in nearly all of the practical cases computed; in the very few cases in which double roots occurred, the input values have been slightly modified to avoid this situation which would necessitate a different program of solution.) The solution of the system of homogeneous algebraic equations when the value of $\lambda_{j}$ is substituted will be denoted as $K_{1}^{j}, \ldots, K_{6}^{j}$. These are in general complex numbers and represent the $j^{\text {th }}$ eigenvector of the matrix of equations (11), which is determined uniquely except for an arbitrary multiplier. The general solution of equations (11) may then be written in the form

$$
F_{i}=C_{1} K_{i}^{1} \mathrm{e}^{\lambda_{1} x}+C_{2} K_{i}^{2} \mathrm{e}^{\lambda_{2} x}+\cdots+C_{6} K_{i}^{6} \mathrm{e}^{\lambda_{6} x} \quad(i=1, \ldots, 6)
$$

where $C_{1}, \ldots, C_{6}$ are arbitrary constants, which in general must be considered as complex although again, as in the case of the eigenvalues, $C_{1}, \ldots, C_{4}$ were usually real and $C_{5}, C_{6}$ were imaginary.

When all incremental applied forces at the boundary are zero $\left(P^{*}=0\right)$, the boundary conditions (9) furnish a system of six linear homogeneous equations for $C_{1}, C_{2}, \ldots, C_{6}$. The critical values of $P_{y}^{0}$ (for a given $P_{x}^{0}$, usually $P_{x}^{0}=0$ ) are then determined by the condition that the determinant of these equations must be zero for buckling to occur. The coefficients of the determinant, however, depend on $P_{y}^{0}$ in a very complicated manner; they are functions of the complex roots and eigenvectors of matrix (11), which do not possess explicit expressions and, according to (12), depend nonlinearly on $s_{y}, c_{y}$, $s_{y}^{\prime}, s_{y}^{\prime \prime}$ which in turn are nonlinear functions of $P_{y}^{0}$. Thus, although the problem has the nature of an eigenvalue problem, it is much more complicated than its usual form. Consequently, some sort of trial-and-error procedure must be applied in an effort to find out for which value of $P_{y}^{0}$ incremental deformation is possible without any incremental loads. The points on the vertical axis of symmetry will be forced to undergo incremental horizontal displacements $u=1-\cos \gamma y$, i.e.

$$
U=0 \text { for } x=0 \text {, and } U_{0}=1
$$


and the values of load parameter $P^{*}$, needed to sustain this deformation, will be determined for various values of $P_{y}^{0}$, until the case $P^{*} \approx 0$ is obtained. The two boundary conditions involving $P^{*}$ in equation (9) are now replaced by condition (16) and the antisymmetry condition $U_{, x}(-a)=U_{, x}(a)$. Together with the remaining four conditions (16), the boundary conditions yield, after substitution of expressions (15) for the new variables $F_{i}$ given by (10), the following nonhomogeneous system of linear algebraic equations for $C_{1}, \ldots, C_{6}$ :

where

$$
\sum_{j} b_{i j} C_{j}=\left\{\begin{array}{l}
0 \text { for } i=1, \ldots, 5 \\
1 \text { for } i=6
\end{array}\right.
$$

$$
\begin{aligned}
& b_{1 j}=\left(K_{4}^{j}-2 K_{5}^{j} s_{x}^{\prime} / s_{x}^{\prime \prime}\right) \mathrm{e}^{-\lambda_{j} a}, b_{2 j}=b_{1 j} \mathrm{e}^{2 \lambda_{j} a} \\
& b_{3 j}=\left(K_{6}^{j}-Q K_{4}^{j}\right) \mathrm{e}^{-\lambda_{j} a}, b_{4 j}=\left(K_{6}^{j}+Q K_{4}^{j}\right) \mathrm{e}^{\lambda_{j} a}, Q=P_{x}^{0} /\left[k_{x} s_{x}\left(1-c_{x}\right)\right] \\
& b_{5 j}=K_{2}^{j}\left(\mathrm{e}^{\lambda_{j} a}+\mathrm{e}^{-\lambda_{j} a}\right), b_{6 j}=K_{1}^{j} .
\end{aligned}
$$

The right-hand sides of these expressions are complex numbers. The value of load parameter $P^{*}$ needed to sustain the imposed incremental deformation may be determined from the first boundary condition (9) which, upon substitution of expressions (15), provides

$$
P^{*}=L_{x} E_{x}^{\prime} \sum_{j=1}^{6} C_{j} K_{2}^{j} \mathrm{e}^{-\lambda_{j} a} .
$$

The above method of solution has been programmed using complex Fortran variables where appropriate (e.g. for $\lambda_{j}, K_{i}^{j}, C_{j}, b_{i j}$ ). The characteristic roots $\lambda_{j}$ and the eigenvectors have been computed using standard library subroutines. The critical value of $P_{y}^{0}$ has been determined by the following procedure, analogous to the 'regula falsi' method: (1) Select some value of $P_{y}^{0}$ and compute the corresponding $P^{*}$. (2) If this $P^{*}$-value is negative, increase, and if it is positive, decrease the $P_{y}^{0}$-value. Then compute again the corresponding $P^{*}$. (3) Continue changing $P_{y}^{0}$ until $P^{*}$ switches sign. Then determine the value of $P_{y}^{0}$ for which $P^{*}$ would vanish if linear interpolation applied, and compute the corresponding $P^{*}$. (4) Correct the value $P_{y}^{0}$ using again linear interpolation, compute new $P^{*}$ etc., until the change in $P^{*}$ is negligible.

In applying the above algorithm, caution is necessary not to use an excessive change in $P_{y}^{0}$ because the lowest critical value could be missed. Nevertheless, after some computing experience only about seven analyses for seven different values of $P_{y}^{0}$ were necessary to find the lowest critical value with about seven digits exact.

\section{NUMERICAL STUDIES}

The solution described above has been programmed in Fortran IV and a number of frames has been analyzed (using computer CDC-6600). In addition to verification of the method, the objective of these studies was to determine the magnitude of the error in comparison with the exact (and more complex) solutions which have been published previously by the authors [3]. The comparison is shown in Fig. 2. It is seen that the micropolar medium is indeed a very good approximation to large regular frames when the overall behavior with axial extensions is considered. One may thus expect the 


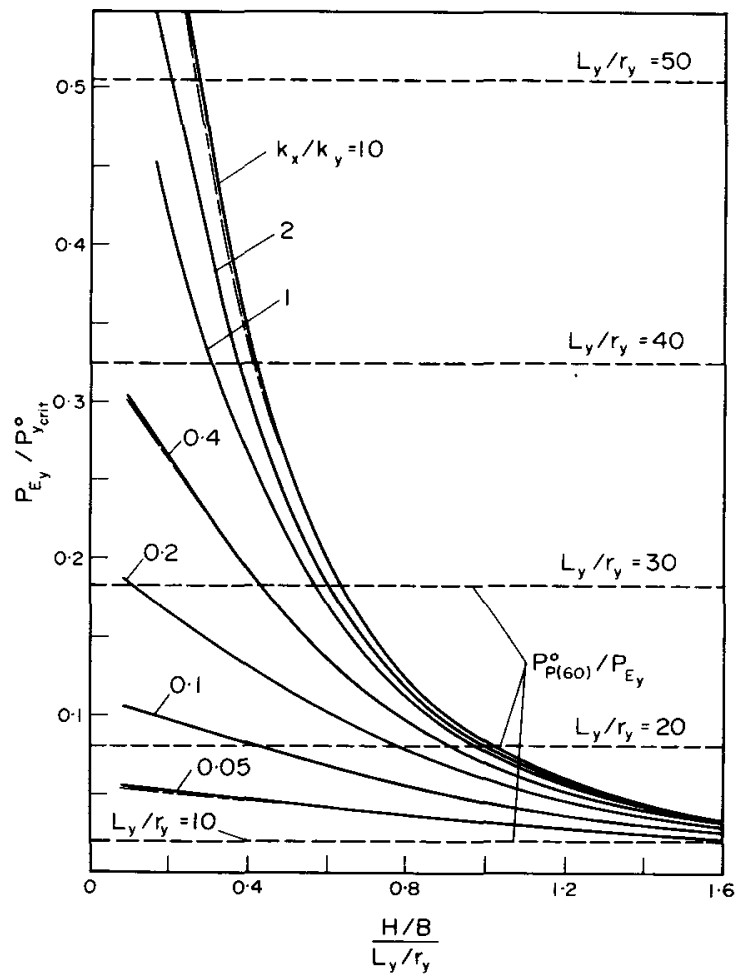

Fig. 2. Critical loads per column for a typical frame. The present solution (dash-dot lines) is undistinguishable from the exact solution given in [3] (solid lines), except where shown.

continuum approximation to yield accurate results even in other situations [4] in which exact solutions are not possible.

Furthermore, it is of interest to make comparison with the buckling loads for shortwave modes without axial extensions. It is known that in such modes, which have usually been considered in analysis, the buckling load is only slightly less than the Euler load for an isolated column (when sway is not prevented). From Fig. 2 it is seen, that in tall frames the long-wave buckling loads can be much smaller.

From Fig. 3 it is seen that for the relatively frequent cases of the higher beam-tocolumn stiffness ratios and very small ratio of frame slenderness $(H / B)$ to column slenderness, the distribution of vertical displacements across the frame width deviates more from the exact solution [3] and has short-wave components. This waving is false and has never been found in the exact solution [3]. But even in these cases the buckling load is still very close to the exact value and the average of the short-wave component approximately coincides with the exact solution.

A discussion of the non-dimensional parameters on which the buckling load depends has been presented in a previous paper[3], on the basis of an exact solution, and thus need not be repeated here.

\section{CONCLUSIONS}

1. In tall building frames with a large number of stories the long-wave buckling 

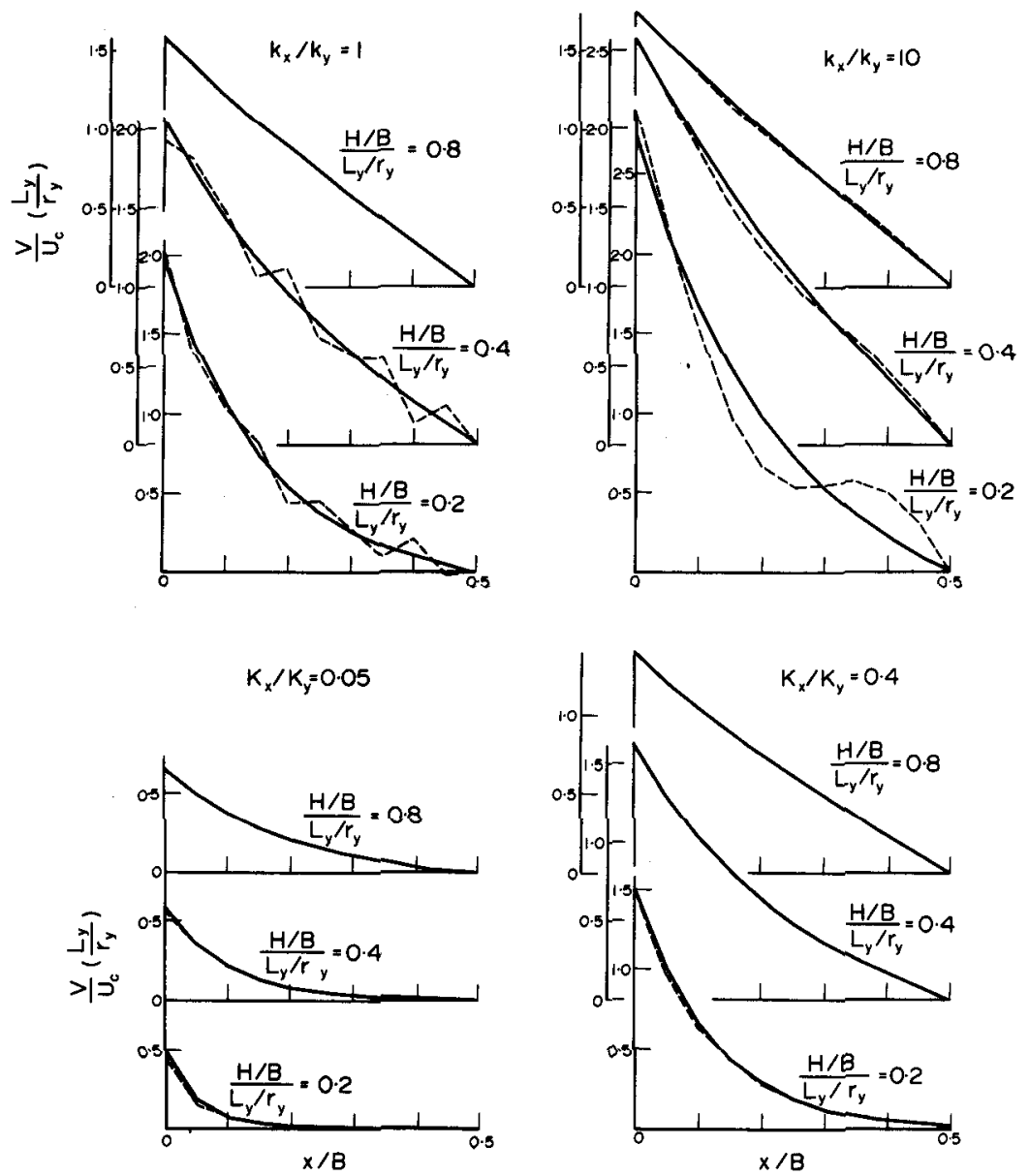

Fig. 3. Distributions of the amplitude or vertical joint displacements across a frame width at buckling for 20 bays per width and various beam-to-column stiffness ratios $k_{x} / k_{y}$, frame heightto-width ratios $H / B$ and column slenderness ratios $L_{y} / r_{y}$. Dashed lines show the present solution where it differs from the exact solution from [3] shown by solid lines. Distribution of column extensions are the same. For $P_{y}^{0}$ less than the buckling value, the distributions are appreciably different (not shown) only if either $P_{y}^{0} / P_{E_{y}}$ is not small or the distribution has shortwave components.

load can be much smaller than the usually considered short-wave buckling load in which axial extensions are neglected.

2. Although the problem has the nature of an eigenvalue problem, it is much more complicated than its usual form because all coefficients of the $6 \times 6$ determinant to vanish depend on the initial stress nonlinearly and in a complicated manner which involves explicitly inexpressible complex roots and eigenvectors of another $6 \times 6$ determinant. Nevertheless, a numerical solution of any desired accuracy can be obtained by a procedure analogous to the 'regula falsi' method.

3. A continuum approximation of large regular frames under initial stress by an orthotropic micropolar medium is a very good model for the study of overall behavior of such frames. 


\section{REFERENCES}

[1] Z. P. BAŽANT and M. CHRISTENSEN, Int. J. Solids Struct. 8, 327 (1972); see also Z. P. Bažant, Developments of Mechanics 6, 587 (1971) (Proc., 12th Midwestern Mechanics Conf.).

[2] C. E. ERINGEN, J. Math. 15, 909 (1966).

[3] Z. P. BAŽANT and M. CHRISTENSEN, J. Struct. Div., Proc. Am. Soc. Civil Engrs. 98, 2269 (1972).

[4] Z. P. BAŽANT and M. CHRISTENSEN, Am. Concrete Institute Special Publ. SP-36, 257, Detroit (1973).

[5] M. A. BIOT, Mechanics of Incremental Deformations, Wiley (1965).

[6] E. H. WU and O. H. WIDERA, Int. J. Solids Struct. 5, 1107 (1969).

[7] Z. P. BAŽANT, Bulletin RILEM 35, 99 (1967).

[8] M. Z. HORNE and W. MERCHANT, The Stability of Frames. Pergamon Press (1965).

$$
\text { (Received } 4 \text { February 1972) }
$$

Résumé-En utilisant une approximation par un milieu continu micropolaire, le flambement extensionel d'une poutre rectangulaire multiétages et multi-sections est résolu en formulant ce problème en termes d'un système de six équations différentielles linéaires ordinaires. Les charges critiques doivent être calculées par un procédé numérique parce que tous les coefficients du déterminant $6 \times 6$ à annuler dépendent explicitement de racines complexes non-exprimables et de vecteurs propres d'un autre déterminant $6 \times 6$ lequel dépend à son tour non linéairement de la contrainte initiale. Il est montré que pour des structures hautes, il est important de considérer des charges de flambement à ondes longues.

Egalement, il est trouvé que l'approximation du milieu continu donne des résultats très précis, comparés avec les solutions exactes des grandes structures.

Zusammenfassung-Unter Verwendung von Annäherung durch ein mikropolares Kontinuum wird die Ausdehnungsknickung eines Baurahmens mit vielen Stöcken und Fächern gelöst. indem das Problem in Ausdrücken von sechs linearen gewöhnlichen Differentialgleichungen formuliert wird. Die Knicklasten muissen durch eine Probiermethode errechnet werden. weil alle Koeffizienten der zu verschwindenden $6 \times 6$ Determinante explizit von inexpressiblen Wurzeln und Eigenvektoren einer anderen 6×6-Determinante abhängen, die wiederum nichtlinear von der Anfangsspannung abhängt. Es wird gezeigt, dass für hohe Rahmen die Berücksichtigung von Langwellenknicklasten wichtig ist. Auch wird gefunden, dass die Kontinuumannäherung im Vergleich mit den exakten Lösungen grosser Rahmen sehr genaue Resultate gibt.

Sommario-Usando approssimazione a mezzo di un continuo micropolare, il problema della deformazione in estenzione di un telaio rettangolare a molti piani e a molte campate e avente confine rettangolare viene risolto formulandolo a mezzo di un sistema di sei equazioni differenziali ordinarie lineari. I carichi producenti la deformazione devono venir calcolati con una procedura per tentativi perché la sparizione di tutti i coefficienti del determinante $6 \times 6$ dipende esplicitamente dalle radici complesse inesprimibili e dagli autovettori di un altro determinante $6 \times 6$ che a sua volta è una funzione non lineare delle sollecitazioni iniziali. Viene dimostrato che per alti telai è importante considerare $\mathrm{i}$ carichi che producono lunghe deformazioni ondulate. Si è scoperto inoltre che l'approssimazione ottenuta col continuo dà risultati molto accurati a paragone delle soluzioni esatte di grandi telai.

Абстракт - На основе аппроксимации микрополярным континуумом проблема раздвижимого выпучивания многоэтажной, многопролетной рамы с прямоугольной границе решается при формулировании его через систему 6 линейных обыкновенных дифференциальных уравнений. Для вычисления критической продольной нагрузки нужно применить метод подбора, так как все коэффициенты определителя $6 \times 6$, обращающиесь в нуль, зависят явно от невыражаемых комплексных корней и собственных векторов другого определителя, который по очереди зависит нелинейно от начального напряжения. Показано, что для высоких рам важно учитывать длинноволновые нагрузки, вызывающие потерь продольной устойчивости. Кроме того, эта аппроксимация позволит получить очень точные результаты в сравнении с точными решениями для больших рам. 